\title{
Genetic Toxicity of three Symmetrical Diselenides in Yeast
}

\author{
Renato M. Rosa, ${ }^{a}$ Temenouga N. Guecheva, ${ }^{b}$ Iuri M. de Oliveira, ${ }^{b}$ Antônio L. Braga ${ }^{c}$ and \\ João A. P. Henriques $*, b, d$ \\ ${ }^{a}$ Laboratório de Genética Toxicológica, Universidade Luterana do Brasil, Canoas-RS, Brazil \\ ${ }^{b}$ Departamento de Biofísica, Instituto de Biociências, Universidade Federal do Rio Grande do Sul, \\ Porto Alegre-RS, Brazil \\ 'Instituto de Química, Universidade Federal de Santa Catarina, Florianópolis-RS, Brazil \\ ${ }^{d}$ Instituto de Biotecnologia, Universidade de Caxias do Sul, Caxias do Sul-RS, Brazil
}

\begin{abstract}
O disseleneto de difenila (DPDS) é um reagente eletrofílico empregado na síntese de diversos compostos organoselenados (OS) farmacologicamente ativos. O objetivo do presente estudo foi investigar os efeitos mutagênicos de três derivados simétricos do DPDS ( $p$-cloro-fenil-disseleneto, $p$-metil-fenil-disseleneto e $p$-metoxi-fenil-disseleneto) em levedura. Em resumo, os efeitos celulares dos três OS estudados nesse trabalho parecem ser variáveis em função do grupo químico substituinte no anel aromático e da concentração empregada. A presença de grupo metila no anel aromático do DPDS aumenta o potencial citotóxico enquanto a inserção de um grupamento metoxila potencializa os efeitos citotóxicos e mutagênicos do DPDS.
\end{abstract}

Diphenyl diselenide (DPDS) is an electrophilic reagent used in the synthesis of a variety of pharmacologically active organoselenium (OS) compounds. The aim of the present study was to investigate the mutagenic effects of three symmetrical derivatives from the prototype DPDS ( $p$-chloride-phenyl-diselenide, $p$-methyl-phenyl-diselenide and $p$-methoxy-phenyl-diselenide) in yeast. In summary, the cellular effects of the three OS compounds studied in this work appear to be variable according to the substituent group in the aromatic ring and are concentration-dependent. The presence of methoxyl group in the aromatic ring of DPDS structure results in elevation of the cytotoxic and mutagenic potential while the introduction of a methyl group increases the cytotoxic effect.

Keywords: organoselenium, diphenyl diselenide, Saccharomyces cerevisiae

\section{Introduction}

Selenium, an essential trace element for animals, is known to have antioxidant and chemopreventive potential in numerous animal model systems as well as cancer chemopreventive efficacy in humans..$^{1-5}$ Ingestion of the major known dietary sources of selenium, such as selenomethionine, selenocysteine and inorganic selenium is limited by toxicity. Thus, a number of synthetic derivatives have been developed. In the last few decades, the interest in organoselenium (OS) biochemistry has intensified due to variety of pharmacologic effects of the synthetic OS compounds. The above molecules could be used as antioxidants, enzyme inhibitors, neuroprotective agents,

\footnotetext{
*e-mail: pegas@ cbiot.ufrgs.br
}

anti-tumor and anti-infectious agents, cytokine inducers and immunomodulators. ${ }^{6,7}$

Diphenyl diselenide (DPDS, Figure 1) is a simple and stable OS compound. It is an electrophilic reagent used in the synthesis of a variety of pharmacologically active OS compounds. ${ }^{8} 9$ Indeed, the biological activity of DPDS has been studied and this compound has become a good candidate for therapeutic proposals, since it presents very interesting pharmacological effects. When compared to other tested diselenide substitutes or ebselen, DPDS exhibits high thiol peroxidase activity and better antioxidant potential as a glutathione peroxidase mimic. ${ }^{2}$ It furthermore has neuroprotective, anti-inflammatory and hepatoprotective properties. ${ }^{8,10}$

However, DPDS also presents toxic effects as it inhibits d-aminolevulinate dehydratase in several tissues 


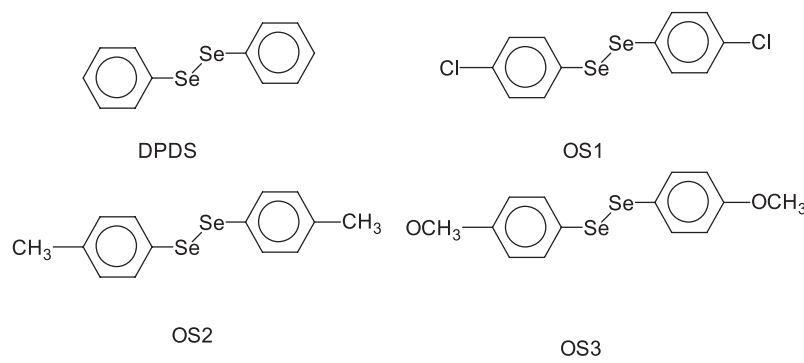

Figure 1. Chemical structure of diphenyl diselenide (DPDS) and three symmetrical diselenide derivatives: $p$-chloride-phenyl-diselenide (OS1); p-methyl-phenyl-diselenide (OS2); and p-methoxy-phenyl-diselenide (OS3).

and organs, as well as voltage-dependent calcium channel and $\mathrm{Na}^{+}-\mathrm{K}^{+}$-ATPase in mouse brain. ${ }^{11,12}$ Moreover, chronic exposure to high doses of DPDS affects the central nervous system, causing seizures, and impairment of glutamatergic transmission and excitotoxicity, as well as liver and renal toxicity. ${ }^{13}$ In microbial models, DPDS was mutagenic and recombinogenic. ${ }^{14}$ Using yeast mutant strains defective in antioxidant defenses, we showed that this OS acts as a pro-oxidant agent by depleting free reduced glutathione (GSH), probably via adduct formation, thus sensitizing the cell to the damaging effect of reactive oxygen species (ROS). ${ }^{15}$ Furthermore, DPDS induced oxidative DNA damage in mammalian cultured V79 cells and in several tissues and organs of mice. ${ }^{16,17}$ In this sense, the development of novel OS compounds derivatives from DPDS without the DNA damaging property seems to be very important.

The aim of the present study was to investigate the mutagenic effects of three symmetrical diselenide derivatives from the prototype DPDS in yeast. This study is intended to determine occupational hazards, to evaluate the safety of possible future pharmacological application, and to explore new biological properties of these compounds. For this purpose, we determined the cytotoxic and mutagenic properties of $p$-chloride-phenyldiselenide (OS1), $p$-methyl-phenyl-diselenide (OS2) and $p$-methoxy-phenyl-diselenide (OS3), using the yeast $S$. cerevisiae as a model organism.

\section{Experimental}

\section{Chemicals}

The organoselenium (OS) compounds OS1, OS2 and OS3 (Figure 1) were kindly provided by Dr. Antônio Carlos Braga, Universidade Federal de Santa Maria (UFSM-RS, Brazil). The chemical purity of OS compounds (99.9\%) was determined by gas chromatography/high-performance liquid chromatography (GC/HPLC). Yeast extract, bacto-peptone, and bacto-agar were obtained from Difco Laboratories (Detroit, MI). Methyl methanesulphonate (MMS), 4-nitroquinoline- $N$-oxide (4-NQO), aminoacids (L-histidine, L-threonine, L-methionine, L-tryptophan, L-leucine, L-lysine) and nitrogen bases (adenine and uracil) were obtained from Sigma (St. Louis, MO, USA). All other reagents were of analytical grade.

\section{Yeast strains and media}

For the mutagenicity evaluation, the haploid strain XV-185-14c was employed (Mata ade2-2 arg 4-17 his 1-7 lys 1-1 trp5-48 hom3-10). The complete medium (YPD) containing $0.5 \%$ yeast extract, $2 \%$ peptone and $2 \%$ glucose was used for routine growth. The minimal medium (MM) contained $0.67 \%$ yeast nitrogen base without amino acids, $2 \%$ glucose, $2 \%$ bacto-agar. The synthetic complete medium (SC) was MM supplemented with $2 \mathrm{mg}$ adenine, $2 \mathrm{mg}$ arginine, $5 \mathrm{mg}$ lysine, $1 \mathrm{mg}$ histidine, $2 \mathrm{mg}$ leucine, $2 \mathrm{mg}$ methionine, $2 \mathrm{mg}$ uracil and $2 \mathrm{mg}$ tryptophan per $100 \mathrm{~mL}$ MM. For plates, the medium was solidified with $2 \%$ bacto-agar. For mutagenesis in XV185-14c strain, the omission medium, lacking lysine (SC-lys), histidine (SC-his) or homoserine (SC-hom) were supplemented with $0.1 \mathrm{mg}$ lysine, histidine or methionine, respectively, per $100 \mathrm{~mL}$ omission medium.

For cell treatment, stock solutions of the used OS compounds were prepared immediately prior to use by dissolution in DMSO. The subsequent dilutions were carried out in distilled water and DMSO concentration in the incubation mixture never exceeded $0.2 \%$. All treatments were carried out in the dark.

\section{Yeast growth}

Stationary cultures were obtained by inoculation of an isolated colony in liquid YPD medium and grown for $48 \mathrm{~h}$ at $30^{\circ} \mathrm{C}$. Cells were harvested and washed twice with saline. The number and proportion of budding cells were determined by counting in a hemocytometer.

\section{Detection of OS-induced reverse and frameshift mutation} in $S$. cerevisiae

A suspension of $2 \times 10^{8}$ cells $/ \mathrm{mL}$ in stationary phase was incubated for $2 \mathrm{~h}$ at $30^{\circ} \mathrm{C}$ with different OS concentrations in phosphate buffered saline solution (PBS) $\mathrm{pH}$ 7.4. After treatment, appropriate cells dilutions were plated onto SC medium to determine cell survival (3-5 days, $30^{\circ} \mathrm{C}$ ), and in the appropriate omission media (7-10 days, $\left.30^{\circ} \mathrm{C}\right)$ to evaluate mutation induction (LYS, HIS, or HOM revertants). 
Whereas his $1-7$ is a non-suppressible missense allele and reversions result from mutation at the locus itself, lys $l-1$ is a suppressible ochre nonsense mutant allele which can be reverted either by locus-specific or forward mutation in a suppressor gene. True reversions and forward (suppressor) mutations at the lys $1-1$ locus were differentiated according to Schuller and von Borstel,${ }^{18}$ where the reduced adenine content of the SC-lys medium shows locus reversions as red and suppressor mutations as white colonies. The hom3-10 mutant allele of haploid strain XV185-14c was used for assaying putative frameshift mutagenesis. It is believed that hom 3-10 contains a frameshift mutation due to its response to a range of diagnostic mutagens. Assays were repeated at least four times and plating was performed in triplicate for each dose.

\section{Statistical analysis}

Data are presented as means \pm standard deviation and analyzed using one-way ANOVA with Dunnett's multiple comparison test. Differences between the control group and different doses of the OS compounds were considered significant when $P<0.05$.

\section{Results}

In Table 1, it can be seen the results of the evaluation of the cytotoxic and mutagenic properties of the several OS compounds. The symmetrical organoselenides employed in this study show different profiles of toxicity in yeast during stationary phase (Table 1). The compound OS1 was not cytotoxic in the concentration range 0.1-100 $\mu \mathrm{M}$ while OS2, that contain a methyl group in the aromatic ring, induce moderate cytotoxicity in the wild type yeast strain in concentrations above $10 \mu \mathrm{M}$. Finally, OS3, an aromatic diselenide containing methoxyl group in the aromatic ring was the most cytotoxic compound, decreasing the cell survival in a dose response manner at concentrations from $1 \mu \mathrm{M}$.

In respect to mutagenic potential, the compound OS1 was not mutagenic in yeast in our experimental conditions. The compound OS2, interestingly, was cytotoxic but it not shows mutagenic potential. In respect to the molecule OS3, it can be seen in Table 1 that the mutation frequency at the hisl, lys 1 and hom 3 loci was significant at almost all concentrations indicating that this molecule is a strong mutagen in yeast.

Table 1. Induction of point mutation (his1-7), ochre allele (lys1-1) and frameshift (hom3-10) mutations in haploid XV185-14c strain of S. cerevisiae after OS treatments in stationary phase

\begin{tabular}{|c|c|c|c|c|c|}
\hline & Treatment & Survival (\%) & $H I S 1 / 10^{7}$ survivors $^{\mathrm{a}}$ & LYS1/10 ${ }^{7}$ survivors ${ }^{\mathrm{b}}$ & HOM $3 / 10^{7}$ survivors \\
\hline Negative Control & & 100 & $1.45 \pm 0.30^{\mathrm{d}}$ & $0.79 \pm 0.26^{\mathrm{d}}$ & $4.21 \pm 1.14^{\mathrm{d}}$ \\
\hline 4NQO & $0.5 \mu \mathrm{g} / \mathrm{mL}^{\mathrm{c}}$ & $40.12 * * *$ & $104.6 \pm 25.0^{* * *}$ & $36.4 \pm 7.54 * * *$ & $50.3 \pm 11.9^{* * *}$ \\
\hline \multirow[t]{5}{*}{ OS1 } & $0.1 \mu \mathrm{M}$ & $96.7 \pm 2.46$ & $2.16 \pm 0.95$ & $1.05 \pm 0.22$ & $5.23 \pm 2.50$ \\
\hline & $1 \mu \mathrm{M}$ & $98.4 \pm 9.60$ & $1.33 \pm 0.14$ & $1.14 \pm 0.35$ & $3.90 \pm 2.10$ \\
\hline & $10 \mu \mathrm{M}$ & $95.5 \pm 3.12$ & $2.07 \pm 0.44$ & $0.90 \pm 0.13$ & $2.45 \pm 1.10$ \\
\hline & $50 \mu \mathrm{M}$ & $98.4 \pm 9.08$ & $1.06 \pm 0.20$ & $0.98 \pm 0.31$ & $2.50 \pm 0.90$ \\
\hline & $100 \mu \mathrm{M}$ & $88.60 \pm 3.90$ & $0.50 \pm 0.10$ & $1.10 \pm 0.25$ & $3.50 \pm 1.10$ \\
\hline \multirow[t]{5}{*}{ OS2 } & $0.1 \mu \mathrm{M}$ & $98.4 \pm 1.50$ & $1.70 \pm 1.00$ & $0.90 \pm 0.30$ & $4.50 \pm 1.25$ \\
\hline & $1 \mu \mathrm{M}$ & $96.3 \pm 0.78$ & $1.35 \pm 0.26$ & $1.70 \pm 0.61$ & $4.13 \pm 0.90$ \\
\hline & $10 \mu \mathrm{M}$ & $80.4 \pm 3.20 *$ & $2.49 \pm 0.55$ & $0.85 \pm 0.05$ & $4.00 \pm 1.60$ \\
\hline & $50 \mu \mathrm{M}$ & $52.3 \pm 2.49 * * *$ & $3.14 \pm 0.91$ & $1.20 \pm 0.56$ & $3.90 \pm 0.67$ \\
\hline & $100 \mu \mathrm{M}$ & $2.0 \pm 0.35 * * *$ & $2.16 \pm 1.10$ & $1.00 \pm 0.16$ & $5.00 \pm 1.44$ \\
\hline \multirow[t]{5}{*}{ OS3 } & $0.1 \mu \mathrm{M}$ & $90.1 \pm 3.00$ & $2.50 \pm 0.49 * * *$ & $0.78 \pm 0.10$ & $6.00 \pm 2.30 * *$ \\
\hline & $1 \mu \mathrm{M}$ & $71.8 \pm 4.98 * * *$ & $3.70 \pm 0.15 * * *$ & $1.30 \pm 0.27 * *$ & $11.50 \pm 3.00 * * *$ \\
\hline & $10 \mu \mathrm{M}$ & $51.5 \pm 11.0 * * *$ & $16.3 \pm 2.10 * * *$ & $9.60 \pm 2.40 * * *$ & $16.50 \pm 0.60 * * *$ \\
\hline & $50 \mu \mathrm{M}$ & $6.90 \pm 0.23 * * *$ & $21.5 \pm 2.40 * * *$ & $17.50 \pm 3.30 * * *$ & $31.30 \pm 2.49 * * *$ \\
\hline & $100 \mu \mathrm{M}$ & $0.5 \pm 0.02 * * *$ & $36.4 \pm 6.00 * * *$ & $35.00 \pm 2.10 * * *$ & $56.06 \pm 5.60 * * *$ \\
\hline
\end{tabular}

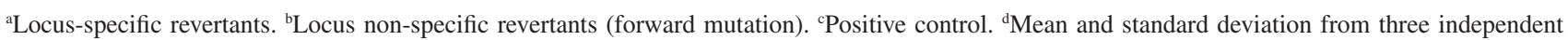
experiments. *Data significant in relation to negative control (not treated) at $* P<0.5$, ** $P<0.01, * * * P<0.001 /$ Anova One-way Dunnett's multiple comparison test. 


\section{Discussion}

A balance between therapeutic versus toxicological effects of certain compound is an important parameter when evaluating its usefulness as a pharmacological drug. In this study, the yeast $S$. cerevisiae was used as model organism to evaluate the mutagenicity and cytotoxicity of three symmetrical diselenides. The yeast Saccharomyces cerevisiae is a useful model for studies of the eukaryotic response to drugs and for investigating the interplay between stress resistance and levels of damaged cell components, such as DNA. Although mutations are often induced in higher frequency in exponential as compared to stationary phase, in this work, we used cells in stationary phase since the metabolic conditions in these phase resemble this of the cells in multicellular organisms in various aspects. Most of the energy in this phase comes from the mitochondrial respiration and the cells are in the $\mathrm{G}_{0}$ phase of the cell cycle where DNA damage accumulates over the time. In stationary phase cell damage cannot be diluted since cell division and new DNA synthesis are not occurring.

The results shown in Table 1 indicate that the OS1 and OS2 compounds possess a wide concentration range in which toxic effects are not observed. These concentrations should be used in future studies evaluating its properties in terms of pharmacological potential. In contrast, compound OS3 is highly cytotoxic in this model. This characteristic is promising for a potential use in the anticancer therapy. The interest in the toxic effects of selenium compounds arose from their cytotoxic activity and from their possible use as chemoprotective agents in the cancer treatment. ${ }^{19-21}$ The cytotoxicity of several molecules (1,3-selenazine derivatives, selenazoles, methylselenol Se-allylselenocysteine, diphenylmethyl selenocyanate, methylseleninic acid, selenazolidine prodrugs and ebselen) has been lately investigated as compounds with these properties could be employed in anti-proliferative therapy. ${ }^{1}$

Selenium in low concentrations may have anticarcinogenic effects, whereas in high concentrations it can be genotoxic and carcinogenic. ${ }^{22}$ Inorganic forms of selenium, such as selenites, produced positive results in the $B$. subtilis rec-assay but did not give any indication of mutagenic activity in the Salmonella/microsome assay. ${ }^{23,24}$ Selenate and selenite were shown to be weakly mutagenic by this assay, giving rise to base-pair substitutions..$^{25}$ The OS3 induced a high level of point and frameshift mutation in yeast (Table 1), which suggests that it could intercalate into DNA.

Chemical compounds with planar topology and electrophilic properties are often capable of intercalation between DNA bases. ${ }^{26}$ Intercalating agent-induced genotoxicity manifests itself primary as frameshift mutagenicity in microbial systems. ${ }^{26}$ Since OS3 is an electrophilic molecule with an aromatic planar structure that induces frameshift mutation, we suggest that this compound is an intercalator mutagen. Frameshift mutations induced by DNA-intercalating drugs have been correlated as well with DNA strand breaks induced by inhibition of DNA topoisomerases. ${ }^{27} \mathrm{~A}$ likewise mode of action may apply to OS3. The organoselenium compound 1,4-phenylenebis(methylene) selenocyanate, known as pXSC, exhibits anti-proliferative effects in mammalian cells through topoisomerase II interference. ${ }^{28}$

On the other hand, organometalloids containing selenium may have the ability to disturb the redox cell cycle in cells at physiological $\mathrm{pH}$ reducing the oxygen to various reactive oxygen species (ROS). ${ }^{29-32}$ Our previous reports show that the cellular effects of DPDS appear to be very complex and the cytotoxicity of DPDS in bacteria, yeast and cultured V79 cells can be ascribed to its ability to deplete GSH, which leads to a pro-oxidant cellular status. Oxidative damage into DNA, inducing modified bases, single and double DNA strand breaks, can also result in frameshift mutation. In this line, breaks generated by free radicals attack to DNA, or during the repair process of the oxidized DNA bases, are repaired by recombinational system or fixed in genome as point and frameshift mutations. In this manner, it is possible that OS3 mutagenic potential also be linked to its ability to generate oxidative stress by thiol depletion, as DPDS. The substitute groups present in the aromatic ring of the compounds OS1 and OS2 probably confer lower capacity than OS3 to disturb the redox homeostasis and/or interact directly with DNA by intercalation, since frameshift mutations are not observed in yeast.

The DNA damaging capacity is useful to trigger signaling pathways that lead to apoptosis in mammalian cells, and this has been considered a promising characteristic in the search of new OS derivative compounds with antitumoral effect. ${ }^{33}$ Several OS molecules of this class, such as diphenylmethylselenocyanate, 1,4-phenylenebis(methylene)-selenocyanate (p-XSC), selenomethionine, and ebselen have interesting antimutagenic and anticarcinogenic effects in a number of systems. . $^{219,34-36}$

Several observations suggest that the groups in the aromatic ring modulate the chemical reactivity of OS compounds, essentially due to modifications of electronegativity in relation to carbon, in the atomic volume and spatial conditions. ${ }^{30}$ When comparing our results with the previous data about DPDS mutagenic activity in yeast (Table 2), we can see differences in relation to the three derivative OS molecules. ${ }^{14,37}$ This observation, suggests that 
Table 2. Comparison of concentration dependent toxic and mutagenic effects (in HIS1, LYS1 and HOM3 loci) between the OS derivatives, DPDS and DPDT in haploid XV185-14c strain of S. cerevisiae after treatment in stationary phase

\begin{tabular}{|c|c|c|c|c|c|}
\hline & Cytotoxicity & HIS1 locus & LYS1 locus & HOM3 locus & Source \\
\hline & $\mathrm{NT} \leq 100 \mu \mathrm{M}$ & NM & NM & NM & Present work \\
\hline & $10 \mu \mathrm{M}$ & NM & NM & NM & Present work \\
\hline & $1 \mu \mathrm{M}$ & $0.1 \mu \mathrm{M}$ & $1 \mu \mathrm{M}$ & $0.1 \mu \mathrm{M}$ & Present work \\
\hline & $120 \mu \mathrm{M}$ & NM & NM & NM & $\begin{array}{c}\text { Machado et al., } 2009 \\
\text { [Ref. 37] }\end{array}$ \\
\hline & $100 \mu \mathrm{M}$ & $100 \mu \mathrm{M}$ & $100 \mu \mathrm{M}$ & $1 \mu \mathrm{M}$ & $\begin{array}{l}\text { Rosa et al., 2004 } \\
\quad \text { [Ref. 14] }\end{array}$ \\
\hline & $10 \mu \mathrm{M}$ & $100 \mu \mathrm{M}$ & $50 \mu \mathrm{M}$ & $5 \mu \mathrm{M}$ & $\begin{array}{c}\text { Degrandi et al., } 2010 \\
\text { [Ref. 38] }\end{array}$ \\
\hline
\end{tabular}

NT: non toxic, NM: non mutagenic; ${ }^{\mathrm{a} D a t a}$ from exponentially growing cells.

the position of methoxyl group substituent can elevate the cytotoxic and genotoxic effects of DPDS, since OS3 is a powerful mutagen in stationary phase cells in contrast to DPDS. The OS3 presented toxic and mutagenic activity in lower doses even in comparison to the diphenyl ditelluride. ${ }^{38}$ Organotellurides are known to present higher reactivity in relation to the structurally related organoselenium compounds due to their higher electronegativity in relation to carbon, which is associated with a larger atomic volume. ${ }^{39,40}$ Furthermore, the introduction of methyl group in OS2 increases only the cytotoxicity of the compound without effect on the mutagenic properties.

\section{Conclusions}

In summary, the cellular effects of the three OS compounds studied in this work appear to be variable according to the substituent group in the aromatic ring and are concentration-dependent. The presence of methoxyl group in the aromatic ring of DPDS structure results in elevation of the cytotoxic and mutagenic potential while the introduction of a methyl group increases the cytotoxic effect. It will be worthwhile to extend the investigation on these compounds in order to elucidate the cellular and molecular mechanisms involved in the observed toxic effects.

\section{Acknowledgments}

This work was supported by Fundação de Amparo à Pesquisa do Estado do Rio Grande do Sul - FAPERGS, Conselho Nacional de Desenvolvimento Científico e Tecnológico - CNPq and Genotox-Royal Institute Genotoxicity Laboratory.

\section{References}

1. Soriano-Garcia, M.; Curr. Med. Chem. 2004, 11, 1657.

2. Nogueira, C. W.; Zeni, G.; Rocha, J. B.; Chem. Rev. 2004, 104, 6255.

3. Whanger, P. D.; Br. J. Nutr. 2004, 91, 11.

4. Letavayová, L.; Vlcková, V.; Brozmanová, J.; Toxicology 2006, $227,1$.

5. Jackson, M. I.; Combs, G. F. Jr.; Curr. Opin. Clin. Nutr. Metab. Care 2008, 11, 718 .

6. Mugesh, G.; du Mont, W. W.; Sies, H.; Chem. Rev. 2001, 101, 2125 . 
7. Bhabak, K. P.; Mugesh, G.; Chemistry 2007, 13, 4594.

8. Rosa, R. M.; Roesler, R.; Braga, A. L.; Saffi, J.; Henriques, J. A.; Med. Bio. Res. 2007, 40, 1287.

9. Naithani, R.; Mini Rev. Med. Chem. 2008, 8, 657.

10. Rosa, R. M.; Flores, D. G.; Appelt, H. R.; Braga, A. L.; Henriques, J. A.; Roesler, R.; Neurosci. Lett. 2003, 341, 217.

11. Barbosa, N. B.; Rocha, J. B.; Zeni, G.; Emanuelli, T.; Beque, M. C.; Braga, A. L.; Toxicol. Appl. Pharmacol. 1998, 149, 243.

12. Borges, V. C.; Rocha, J. B.; Nogueira, C. W.; Toxicology 2005 , $215,191$.

13. Moretto, M. B.; Rossato, J. I.; Nogueira, C. W.; Zeni, G.; Rocha, J. B.; J. Biochem. Mol. Toxicol. 2003, 17, 154.

14. Rosa, R. M.; Sulzbacher, K.; Picada, J. N.; Roesler, R.; Saffi, J.; Brendel, M.; Henriques, J. A.; Mutat. Res. 2004, 563, 107.

15. Rosa, R. M.; de Oliveira, R. B.; Saffi, J.; Braga, A. L.; Roesler, R.; Dal-Pizzol, F.; Fonseca, J. C. M.; Brendel, M.; Henriques, J. A.; Life Sci. 2005, 77, 2398.

16. Rosa, R. M.; do Nascimento Picada, J.; Saffi, J.; Henriques, J. A.; Mutat. Res. 2007, 628, 87.

17. Rosa, R. M.; Hoch, N. C.; Furtado,G. V.; Saffi, J.; Henriques, J. A.; Mutat. Res. 2007, 633, 35.

18. Schuller, R. C.; Von Borstel, R. C.; Mutat. Res. 1974, 24, 17.

19. Brenneisen, P.; Steinbrenner, H.; Sies, H.; Mol. Aspects Med. 2005, 26, 256.

20. El-Bayoumy, K.; Sinha, R.; Mutat. Res. 2005, 591, 224.

21. El-Bayoumy, K.; Sinha, R.; Mutat. Res. 2004, 551, 181.

22. Valdiglesias, V.; Pásaro, E.; Méndez, J.; Laffon, B.; Arch. Toxicol. 2010, 84, 337.

23. Nakamuro, K.; Yoshikawa, Y.; Sayato, Y.; Kurata, H.; Tonomura, M.; Tonomura, A.; Mutat. Res. 1976, 40, 177.

24. Lofroth, G.; Ames, B. N.; Mutat. Res. 1978, 53, 65.

25. Noda, M.; Takano, T.; Sakurai, H.; Mutat. Res. 1979, 66, 175.

26. Snyder, R.; Arnone, M.; Mutat. Res. 2002, 503, 21.
27. Sung, P.; Trujillo, K. M.; Van Komen, S.; Mutat. Res. 2000, $451,257$.

28. Cho, K. H.; Pezzuto, J. M.; Bolton, J. L.; Steele, V. E.; Kelloff, G. J.; Lee, S. K.; Constantinou, A.; Eur. J. Cancer. 2000, 36, 2146.

29. Valko, M.; Rhodes, C. J.; Moncol, J.; Izakovic, M.; Mazur, M.; Chem. Biol. Interact. 2006, 160, 1.

30. Giles, N. M.; Watts, A. B.; Giles, G. I.; Fry, F. H.; Littlechild, G. A.; Jacob, C.; Chem. Biol. 2003, 10, 677.

31. Jacob, C.; Giles, G. I.; Giles, N. M.; Sies H.; Angew. Chem. Int. Ed. Engl. 2003, 42, 4742.

32. Klotz, L. O.; Kröncke, K. D.; Buchczyk, D. P.; Sies, H.; J. Nutr. 2003, 133, 1448S.

33. Zhou, N.; Xiao, H.; Li, T. K.; Nur-E-Kamal, A.; Liu, L. F.; J. Biol. Chem. 2003, 278, 29532.

34. Kumar, Y.; Green, R.; Borysko, K.; Wise, D.; Wotring, L.; Towsend, L.; J. Med. Chem. 1993, 36, 3843.

35. Yang, C.; Shen, H.; Ong, C.; Arch. Biochem. Biophys. 2000, $374,142$.

36. Das, R. K.; Hossain, S. K.; Bhattacharya, S.; Cancer Lett. 2005, 230, 90.

37. Machado, M. da S.; Villela, I. V.; Moura, D. J.; Rosa, R. M.; Salvador, M.; Lopes, N. P.; Braga, A. L.; Roesler, R.; Saffi, J.; Henriques, J.A.; Mutat. Res. 2009, 673, 133.

38. Degrandi, T. H.; de Oliveira, I. M.; d'Almeida, G. S.; Garcia, C. R.; Villela, I. V.; Guecheva, T. N.; Rosa, R. M.; Henriques, J. A.; Mutagenesis 2010, 25, 257.

39. Khurana, J. M.; Agrawal, A.; Kumar, S.; J. Braz. Chem. Soc. 2009, 20, 1256.

40. Alves, D.; Pena, J. M.; Vieira, A. S.; Botteselle, G. V.; Guadagnin, R. C.; Stefani, H. A.; J. Braz. Chem. Soc. 2009, 20,988 . 